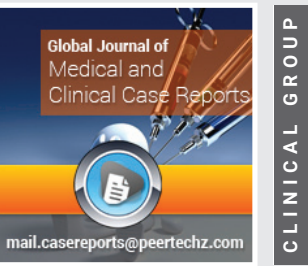

\title{
Alkaline diet and long term preservation of renal function in
} stage 5 CKD

\author{
Athanasiadou V, Kiousi E, Panokostas D and Grapsa E* \\ National and Kapodistrian University of Athens, Nephrology Department of Aretaieio Hospital, Athens \\ Greece
}

Received: 30 April, 2020

Accepted: 23 May, 2020

Published: 25 May, 2020

*Corresponding author: Eirini Grapsa MD, Associate Professor, Department of Nephrology, National and Kapodistrian, University of Athens, Aretaieio, Hospital, Athens, Greece, E-mail: egrapsa@aretaieio.uoa.gr Keywords: Kidney disease; Alkaline diet; Nutrition https://www.peertechz.com

Check for updates

\begin{abstract}
Kidneys produce bicarbonate ions that neutralize acids in the blood. Patients suffering from Chronic Kidney Disease (CKD) often present metabolic acidosis, as the kidney can no longer neutralize the acid load. Alkaline diet based on fruits, vegetables and mostly plant protein may have a positive effect on long-term preservation of the renal function in patients with stage 4-5 CKD while maintaining the nutritional status.
\end{abstract}

\section{Introduction}

Chronic Kenal Disease (CKD) is accompanied by a reduced ability to excrete acid which has detrimental effects on acid-base balance, bone and cardiovascular disease [1].

Depending on the type of food, the metabolic residue may be acidic, neutral or alkaline.

Recent studies show that increasing fiber intake reduces renal impairment and disease progression $[2,3]$.

In this paper we present the correlation of alkaline diet and long term preservation of renal function in a patient who presented with a post-surgery acute renal injury, started on dialysis and gradually withdrew from it with an eGFR $\approx 13 \mathrm{ml} /$ $\min / 1.73 \mathrm{~m}$. He remained free of dialysis for 2.5 years while maintaining an excellent nutritional state.

\section{Case report}

A 73-year-old male patient with a history of high blood pressure and coronary heart disease for over 20 years, type 2 diabetes since 2016 with no concomitant kidney disease developed acute renal injury after abdominal vascular surgery and eventually started on dialysis. After 6 months on dialysis the patient's renal function gradually started to improve. Initially we reduced the number of sessions from 3 to 2 weekly 4hours sessions and we monitored his renal function regularly.
Within the next 4 months he completely withdrew from dialysis with $\mathrm{eGFR} \approx 13 \mathrm{ml} / \mathrm{min} / 1.73 \mathrm{~m}$ and diuresis $\approx 1200 \mathrm{ml} / 24 \mathrm{~h}$.

Right from the beginning, the patient was put on an alkaline diet with documentation of his protein mostly white meat and fish 3 time per week , 2-3 servings of fruit and 1-2 servings of vegetables per day. He replaced dairy products with soy alternatives non-enriched with phosphorus-containing additives. Vegetables were thoroughly soaked before cooking in order to reduce the amount of potassium they contained. Based on literature, he received oral supplements of sodium bicarbonate 500mg twice a day [4-6].

He underwent regular clinical monitoring and control of renal function and nutrition indicators, initially every 15 days, thereinafter every month and every two months for 2.5 years. The parameters of renal function that we measured were creatinine, urea, eGFR (Modification of Diet in Renal Disease (MDRD) Study equation) and hemoglobin levels, while the nutrition status was monitored by BMI, total blood proteins and albumin levels.

Two years from the beginning of the follow up the patient was admitted to the hospital. He suffered heart failure decompensation following a possible non-ST-segment elevation myocardial infarction (NSTEMI). His eGFR fell from 12 to $9.5 \mathrm{ml} / \mathrm{min} / 1.73 \mathrm{~m}$, but dialysis was not initialed; he remained on an alkaline diet and oral sodium bicarbonate. Two 
months later the eGFR started to improve, reaching almost $13 \mathrm{ml} / \mathrm{min} / 1.73 \mathrm{~m}$. Six months later he suffered another decline in his renal function, following a respiratory infection and due to uremic symptoms, he was reintroduced on dialysis with residual diuresis $\approx 1000 \mathrm{ml} / 24 \mathrm{~h}$.

Our results showed that the patient's eGFR remained almost unchanged throughout the follow-up (Figure 1), with exception of the first month following the myocardial infarction. Hemoglobin levels varied between 10.9 and 13.8 gr/dl (Figure 2). Plasma proteins levels remained unchanged (Figure 3) throughout the 2.5 years of follow-up. His BMI levels, on the other hand, did suffer a significant decrease during hospitalization due to NSTEMI that never return to prior levels, still remained within a normal range of 22,8 to 23,5 (Figure 4).

\section{Discussion}

Acid is produced mainly from the metabolism of proteins and alkali from organic anions, such as citric and acetic acid, which are naturally bound to cations such as potassium [7].

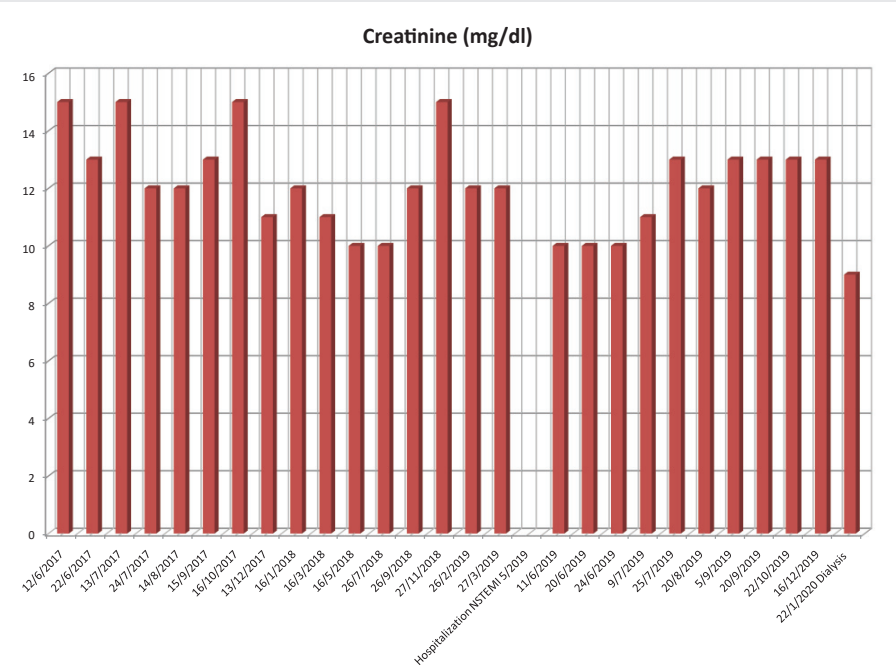

Figure 1a: Creatinine (mg/dl).

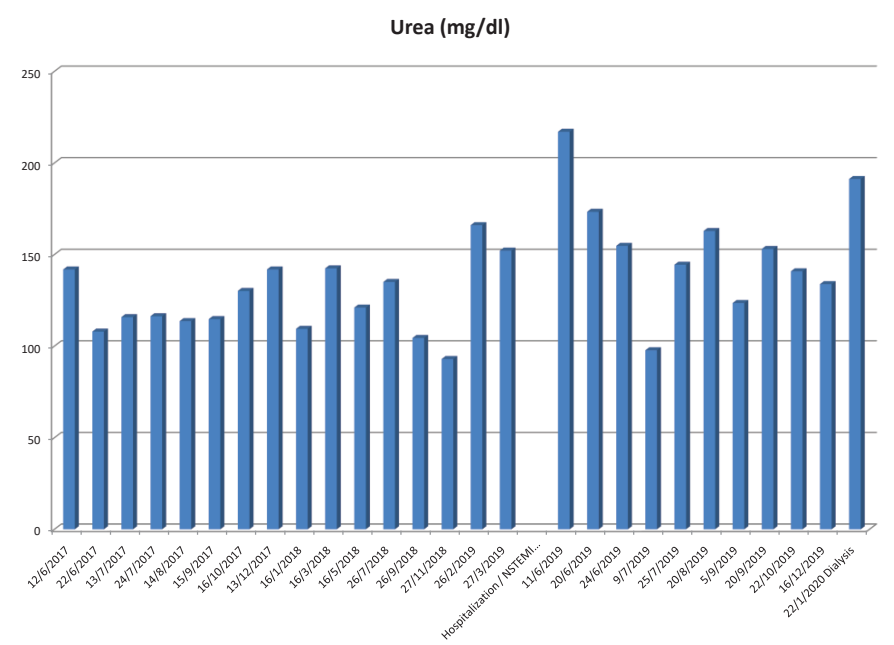

Figure 1b: Urea (mg/dl).
$\mathrm{Hb}(\mathrm{g} / \mathrm{dl})$
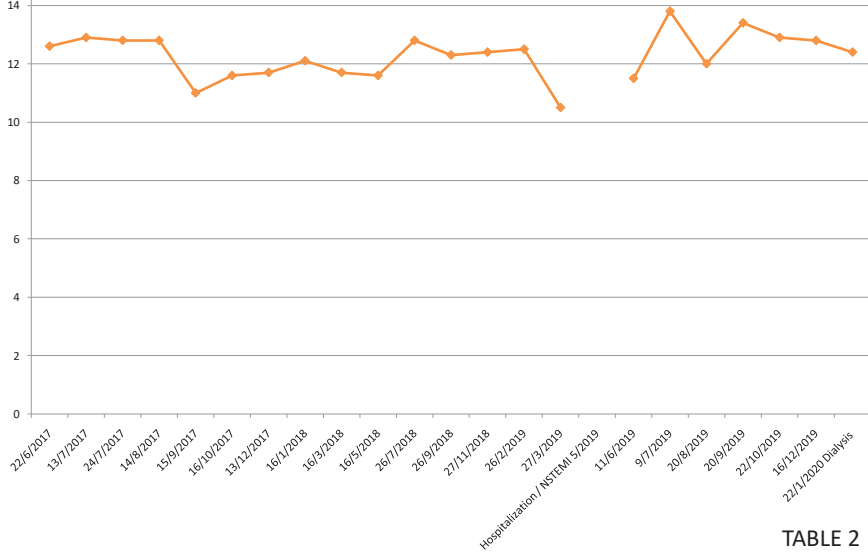

Figure 2: $\mathrm{Hb}(\mathrm{g} / \mathrm{dl})$.

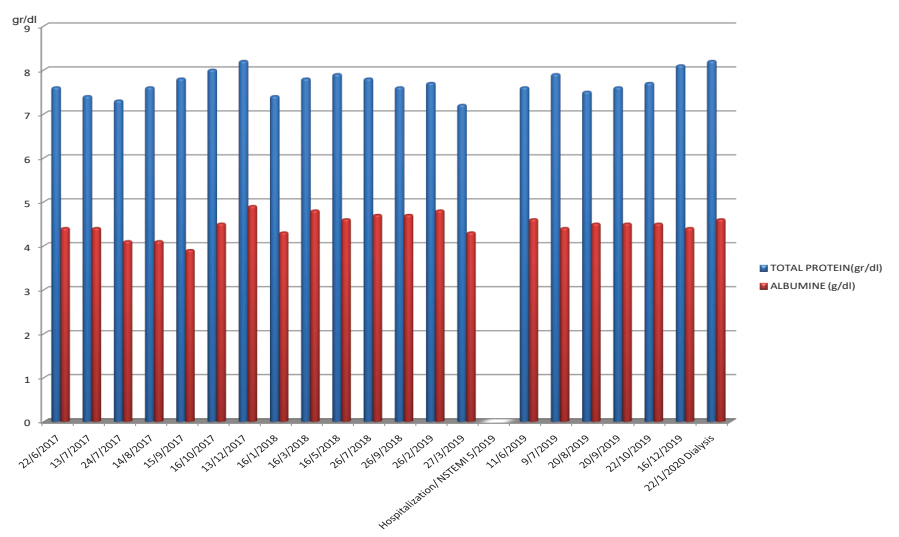

Figure 3: Plasma proteins levels.

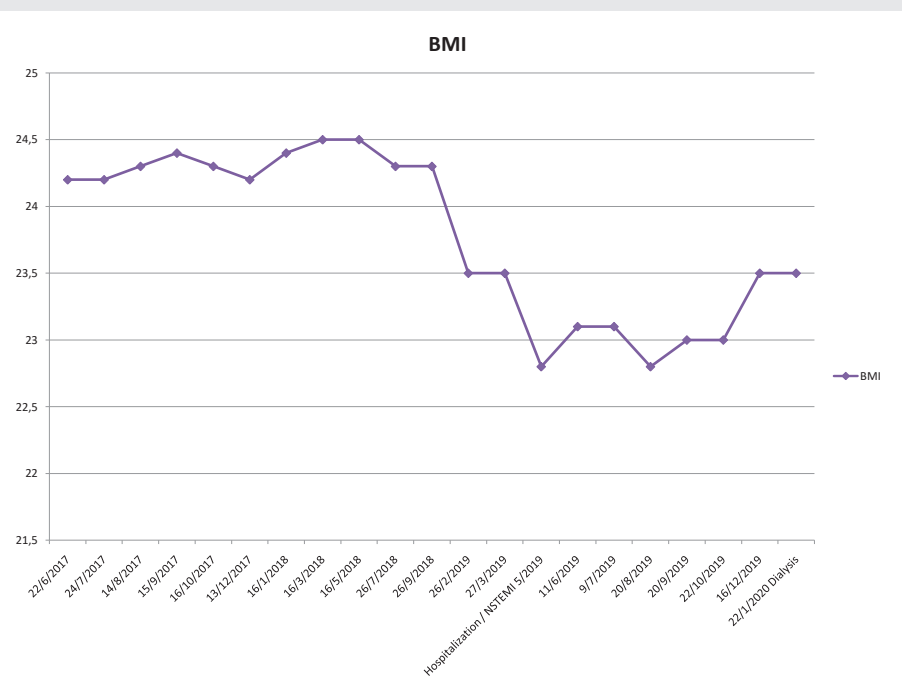

Figure 4: BMI.

Acid is excreted with phosphate. Patients suffering from chronic kidney disease present a limited capacity of acid excretion which eventually leads to a displacement of acidbase equilibrium in metabolic acidosis. When this happens, 
bicarbonate levels fall and bones and muscles are consumed in order to neutralize the acid.

Consumption of plant proteins has been shown to reduce the production of endogenous acids and therefore the amount of acid that the kidneys need to manage. Thus, the secretion of angiotensin II, aldosterone and endothelin, necessary for the excretion of acid from the distal tube, is less stimulated, while the production of ammonia in the proximal tube is reduced $[8,9]$. In 2014, Goraya, et al. [10], measured the levels of urine excretion of angiotensinogen and plasma cysGFR of 108 patients who followed a 36 months dietary acid reduction with oral bicarbonate supplementation and diet based on fruits and vegetables. The results showed statistically significant higher cysGFR in these patients in respect to controls.

A plant-based diet also seems to alter the intestinal flora which may lead to increased production of short-chain fatty acids or alkali and thus, fewer nephrotoxic metabolites [11] In 2019, Laffin et al. published the results of a double-blind, randomized, placebo-controlled trial that compared dietary supplementation of amylose resistant starch (HAM-RS2) with placebo in patients with end-stage CKD. They showed that microbial manipulation in CKD patients induced by the consumption of fiber may exert an anti-inflammatory effect through an elevation in the bacterial flora [12].

As a conclusion, by a regular clinical monitoring we observed that the reduction of the acid load through a diet low in animal protein and high in plant protein had a beneficial effect on maintaining steady eGFR allowing him to remain free of dialysis for 2.5 years while maintaining an excellent nutritional status. More studies need to be conducted in order to establish the best diet protocol for different patients.

\section{References}

1. Brown L, Luciano A, Pendergast J, Khairallah P, Anderson CAM, et al. (2019) Predictors of Net Acid Excretion in the Chronic Renal Insufficiency Cohort (CRIC) Study. Am J Kidney Dis 74: 203-212. Link: https://bit.ly/2Tx3wEN
2. Passey C (2017) Reducing the Dietary Acid Load: How a More Alkaline Diet Benefits Patients with Chronic Kidney Disease. J Ren Nutr 27:151-160. Link: https://bit.ly/2A3aYAl

3. Siener R (2018) Dietary Treatment of Metabolic Acidosis in Chronic Kidney Disease. Nutrients 10: E512. Link: https://bit.ly/3bVWLTk

4. Hu MK, Witham MD, Soiza RL (2019) Oral Bicarbonate Therapy in NonHaemodialysis Dependent Chronic Kidney Disease Patients: A Systematic Review and Meta-Analysis of Randomised Controlled Trials. J Clin Med 8: 208. Link: https://bit.ly/2TrXPHW

5. de Brito-Ashurst I, Varagunam M, Raftery MJ, Yaqoob MM (2009) Bicarbonate supplementation slows progression of CKD and improves nutritional status. $J$ Am Soc Nephrol 20: 2075-2084. Link: https://bit.ly/2WT9rWN

6. Shah S, Abramowitz M, Hostetter T, Melamed M (2009) Serum bicarbonate levels and the progression of kidney disease: a cohort study. Am J Kidney Dis 54: 270-277. Link: https://bit.ly/36tVGB6

7. Scialla JJ, Anderson CAM (2013) Dietary acid load: A novel nutritiona target in chronic kidney disease? Adv Chronic Kidney Dis 20: 141-149. Link: https://bit.ly/3em $1 \mathrm{klj}$

8. Wesson DE (2006) Regulation of kidney acid excretion by endothelins. Kidney International 70: 2066-2073. Link: https://bit.ly/2LRWEgM

9. Kelly JT, Palmer SC, Wai SN, Ruospo M, Carrero JJ, et al. (2017) Healthy Dietary Patterns and Risk of Mortality and ESRD in CKD: A MetaAnalysis of Cohort Studies. Clin. J Am Soc Nephrol 12: 272-279. Link: https://bit.ly/2WRIblb

10. Goraya N, Simoni J, Jo CH, Wesson DE (2014) Treatment of metabolic acidosis in patients with stage 3 chronic kidney disease with fruits and vegetables or oral bicarbonate reduces urine angiotensinogen and preserves glomerular filtration rate. Kidney Int 86: 1031-1038. Link: https://bit.ly/3ggBqan

11. Kieffer DA, Piccolo BD, Vaziri ND, Liu S, Lau WL, et al. (2016) Resistant starch alters gut microbiome and metabolic profiles concurrent with amelioration of chronic kidney disease in rats. Am J Physiol 310: F857-F871. Link: https://bit.ly/2XjON10

12. Laffin MR, Tayebi Khosroshahi H, Park H, Laffin LJ, Madsen K, et al. (2019) Amylose resistant starch (HAM-RS2) supplementation increases the proportion of Faecalibacterium bacteria in end-stage renal disease patients: Microbial analysis from a randomized placebo-controlled trial. Hemodial Int 23: 343-347. Link: https://bit.ly/3gfjrRG

\section{Discover a bigger Impact and Visibility of your article publication with}

Peertechz Publications

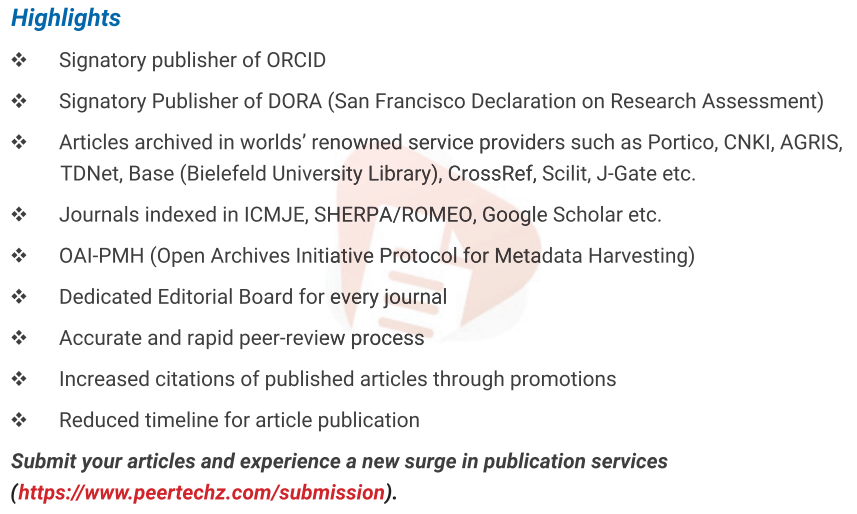

Peertechz journals wishes everlasting success in your every endeavours.

Copyright: @ 2020 Athanasiadou V, et al. This is an open-access article distributed under the terms of the Creative Commons Attribution License, which permits unrestricted use, distribution, and reproduction in any medium, provided the original author and source are credited. 